\title{
Risk perception of cardiovascular diseases among individuals with hypertension in rural Malaysia
}

\author{
Nazar Mohd Zabadi Mohd Azahar, ${ }^{1}$ Ambigga Devi S Krishnapillai, ${ }^{2}$ Noor Hanita Zaini, ${ }^{3}$ \\ Khalid Yusoff ${ }^{4,5}$
}

'Department of Medical Laboratory Technology, Faculty of Health Sciences, Universiti Teknologi MARA Pulau Pinang, Bertam Campus

${ }^{2}$ Faculty of Medicine \& Defence Health, National Defence University of Malaysia, Kuala Lumpur, Malaysia

${ }^{3}$ Department of Nursing Science, Faculty of Medicine, University of Malaya, Kuala Lumpur, Malaysia

${ }^{4}$ UCSI University, Kuala Lumpur, Malaysia

${ }^{5}$ Department of Cardiology, Faculty of Medicine, Universiti Teknologi MARA, Kuala Lumpur, Malaysia

Correspondence to Nazar Mohd Zabadi Mohd Azahar, Department of Medical Laboratory Technology, Faculty of Health Sciences, Universiti Teknologi MARA, Pulau Pinang, Bertam Campus, Malaysia; nazarzabadi@gmail.com

Received 22 November 2016 Revised 3 June 2017 Accepted 9 July 2017
ABSTRACT

Objective Despite various efforts, hypertension remains poorly controlled, thus allowing cardiovascular disease (CVD) to impact the health burden worldwide. Patients' perception of risk may contribute to this scenario. The present study aims to assess the level of risk perception among individuals with hypertension in rural Malaysia. Methods This is a community-based study conducted among adults between 2010 and 2011 among a rural population in Raub, Pahang, Malaysia. Blood pressure was measured after 5 min of rest. Measurement was done twice and the average was recorded. Cardiovascular risk perception score (CVRPS) was derived using the Modified Risk and Health Behavior Questionnaire. Higher CvRPS indicates the respondent perceives a poorer prognostic outlook.

Results A total of 383 respondents who have hypertension participated in this study. The mean age of respondents was $62 \pm 10.6$ years; men $63.1 \pm 9.6$ years, women $61.2 \pm 11.1$ years ( $p>0.05)$. Among hypertensives, those who were not on medication had significantly lower CVRPS compared with those who were on medications (115.9 \pm 22 . 1vs $120.9 \pm 23.5, p=0.036)$; those who were not aware of their hypertensive status had significantly lower CvRPS compared with respondents who were aware about their hypertension $(116.7 \pm 22.5 v s 121.7 \pm 21.3, p=0.029)$ and those with uncontrolled hypertension had significantly lower CVRPS compared with those whose blood pressure was controlled (118.2 \pm 22.2 vs $128.8 \pm 25.8, p=0.009$ ).

Conclusions Our study shows that respondents who were not on medications, unaware of their hypertension status and those who had uncontrolled hypertension tended to underestimate (lower CvRPS) their risk for CVD. Improving their CVPRS through a concerted health education may lead to better therapeutic behaviour and outcomes.

\section{INTRODUCTION}

Risk perception is the assessment of an individual's subjective appraisal of vulnerability or personal harm. ${ }^{1}$ It is an evaluation of the odds of having a specified event in the future.

Perception of risk should be determined especially among high-risk patients as an aid in health education. It is helpful in the risk dialogue or during patient consultation or counselling. ${ }^{2}$ Knowing patients' concerns and how patients perceive their risk are important initial steps in appropriately managing the risk. ${ }^{34}$ There are some theories that provide an insight into this issue. Health Belief Model and the Protection Motivation Theory are some of the examples that try to explain the association between perceptions of risk with health behaviour. These theories emphasise that perception of risk is important in educating patients on their health-seeking behaviour including preventive measures. ${ }^{56}$

Individuals who underestimate their future risk for a certain disease tend to have low motivation for changes in health behaviour ${ }^{7}$ including low compliance with medical treatment. Conversely, a high score in perception of risk is associated with positive health-seeking behaviours and motivation to change lifestyle. ${ }^{8}$

Although there has been much effort on risk factor modification, high-risk individuals often fail to change their behaviours. ${ }^{19}$ Underestimation of risk has been proposed to account for this discrepancy. Failure to have appropriate level of perception might prevent individuals from making a significant change in their lifestyles. ${ }^{10} 11$ Perhaps the key to overcoming this ongoing conundrum is to focus on risk perception of individuals as an entry into engaging them into appropriate health-seeking behaviour. ${ }^{812}$

Hypertension is one of the main risk factors for developing cardiovascular disease (CVD). Controlling hypertension is a major issue worldwide. Many factors have been identified in the low rates of controlling hypertension such as availability, accessibility, affordability and acceptability of therapeutic regimens. Thus far, only a few studies focused on patients' own perspective, that is, how they view or perceive their risk of developing CVD. As risk perception plays an important role in behavioural changes, it can be used to improve the CVD awareness and knowledge among the rural populations. Subsequently, it will contribute in circumventing the current spread of CVD in the community. This study was aimed to measure the level of risk perception among individuals with hypertension in rural Malaysia.

\section{METHODS}

This is a community-based study carried out in rural communities in Raub, Pahang, between 2010 and 2011. Participants were randomly selected from among those in a previous study. ${ }^{13}$ Individuals who have hypertension were included in this study. Blood pressure was measured by an Omron automatic blood pressure monitor (Shanghai, China). An average of two readings was taken after the participants had a $5 \mathrm{~min}$ rest. Hypertension was defined as blood pressure $\geq 140 / 90 \mathrm{~mm} \mathrm{Hg}$ or on antihypertensive medications. 


\begin{tabular}{|c|c|c|}
\hline Characteristics & Frequency (n) & Percentage (\%) \\
\hline Sex & $n=383$ & \\
\hline Male & 157 & 41.0 \\
\hline Female & 226 & 59.0 \\
\hline Age (years) & $\mathrm{n}=383$ & \\
\hline $30-50$ & 60 & 15.7 \\
\hline $51-60$ & 129 & 33.7 \\
\hline $61-70$ & 95 & 24.8 \\
\hline$>70$ & 99 & 25.8 \\
\hline Highest educational attainment & $n=379$ & \\
\hline No formal education & 57 & 14.9 \\
\hline Primary school & 255 & 66.6 \\
\hline Secondary school & 67 & 17.5 \\
\hline Marital status & $n=380$ & \\
\hline Single/divorced & 84 & 22.1 \\
\hline Married & 296 & 77.9 \\
\hline Monthly household income (RM) & $\mathrm{n}=371$ & \\
\hline$\leq 500$ & 94 & 25.3 \\
\hline $501-1500$ & 213 & 57.4 \\
\hline $1501-2500$ & 51 & 13.7 \\
\hline$>2500$ & 13 & 3.5 \\
\hline Current smokers & 50 & 13.2 \\
\hline On treatment & 173 & 46.4 \\
\hline Aware of hypertension & 180 & 47.7 \\
\hline Controlled hypertension & 44 & 25.4 \\
\hline
\end{tabular}

RM, Ringgit Malaysia.

The Risk and Health Behaviors Questionnaire developed by Britta Renner and Ralf Schwarzer $(2005)^{14}$ was modified and piloted before use in this study. ${ }^{15}$ Cardiovascular risk perception score (CvRPS) was assessed by a 28 -item questionnaire. Each item was given a Likert scale ranging from 1 to 7 . Total of the score was calculated, and this represented the cardiovascular risk perception score. Sociodemographic properties of respondents such as age, sex, level of education, smoking status and medical history were recorded. Institutional ethics board approval and informed consent were obtained prior to the commencement of the study. Statistical Package for the Social Sciences V.20 was used for analysis. Frequency and percentages with 95\% CI were used to describe the sociodemographic properties of the respondents. Independent t-test was used to determine whether there is a significant difference between cardiovascular risk perception score with sex, marital status, smoking status, medication, awareness and status of hypertension control. One-way analysis of variance was used to determine whether there is a significant difference between cardiovascular risk perception score with age groups, highest educational attainment, household income and blood pressure status of the respondents.

\section{RESULTS}

Table 1 shows the sociodemographic characteristics of the respondents. The mean age of respondents in this study was $62 \pm 10.6$ years. The study population was predominantly women $(59 \%)$, aged 51-60 years old (33.7\%), had primary education (66.6\%), married (77.9\%) and had a monthly household income ranging from RM501 to RM1500 (57.4\%). Furthermore, 13.2\% were smokers while $46.4 \%$ of respondents were on medication to treat hypertension and $25.4 \%$ had their hypertension controlled.
Table 2 CVRP score among hypertensives $(n=383)$

\begin{tabular}{|c|c|c|c|}
\hline & & $\begin{array}{l}\text { Mean CvRPS score } \\
(95 \% \mathrm{Cl})\end{array}$ & p Value \\
\hline \multirow{4}{*}{$\begin{array}{l}\text { Age of } \\
\text { respondents } \\
\text { (years) }\end{array}$} & $30-50$ & 124.1 (117.3 to 130.8$)$ & \multirow[t]{4}{*}{0.028} \\
\hline & $51-60$ & $121.4(117.4$ to 125.5$)$ & \\
\hline & $61-70$ & $116.2(111.4$ to 121.1$)$ & \\
\hline & $>70$ & $114.4(110.2$ to 118.7$)$ & \\
\hline \multirow[t]{2}{*}{ Sex of respondents } & Male & $119.0(115.3$ to 122.8$)$ & \multirow[t]{2}{*}{0.636} \\
\hline & Female & $117.9(114.8$ to 121.0$)$ & \\
\hline \multirow[t]{2}{*}{ Marital status } & Single/divorced & $113.3(109.4$ to 117.1$)$ & \multirow[t]{2}{*}{0.024} \\
\hline & Married & $119.8(117.0$ to 122.5$)$ & \\
\hline \multirow{3}{*}{$\begin{array}{l}\text { Highest } \\
\text { educational } \\
\text { attainment }\end{array}$} & No formal education & 110.9 (105.6 to 116.1$)$ & \multirow[t]{3}{*}{0.025} \\
\hline & Primary school & $118.8(115.9$ to 121.7$)$ & \\
\hline & Secondary school & 122.3 (116.4 to 128.2$)$ & \\
\hline \multirow[t]{2}{*}{ Smoking status } & Smokers & 119.3 (113.0 to 125.6$)$ & \multirow[t]{2}{*}{0.781} \\
\hline & Non-smokers & 118.3 (115.7 to 120.9$)$ & \\
\hline \multirow{4}{*}{$\begin{array}{l}\text { Household } \\
\text { income/month }\end{array}$} & $\leq \mathrm{RM} 500$ & $110.3(106.2$ to 114.4$)$ & \multirow{4}{*}{$<0.001$} \\
\hline & RM501-RM1500 & 119.5 (116.4 to 122.7$)$ & \\
\hline & RM1501-RM2500 & 128.4 (120.8 to 136.0$)$ & \\
\hline & $>$ RM2500 & $107.1(94.3,119.9)$ & \\
\hline
\end{tabular}

CVRP, cardiovascular risk perception; RM, Ringgit Malaysia.

The mean cardiovascular risk perception score was $118 \pm 25.7$. The score ranged from 34 to 185 . The score was significantly associated with age $(p=0.028)$, marital status $(p=0.024)$, highest educational attainment $(p=0.025)$ and household income of the respondents $(p<0.001)$. In contrast, sex of respondents and smoking status were not significantly associated with cardiovascular risk perception score (table 2).

The score was not significantly associated with blood pressure status $(p=0.532)$. However, hypertensive respondents who were not on antihypertensive medications had significantly lower cardiovascular risk perception score compared with those who were on antihypertensive medications $(p=0.036)$. Furthermore, hypertensives who were not aware of their hypertension status had significantly lower cardiovascular risk perception score $(p=0.029)$. In addition, respondents with uncontrolled hypertension had lower cardiovascular risk perception score compared with those who had their blood pressure controlled $(\mathrm{p}=0.009)($ table 3$)$.

\section{DISCUSSION}

Older hypertensives in this study tend to underestimate their risk for CVD events. Our finding is consistent with a study done in the USA ${ }^{16}$ as well as in the Nottingham Health Profile study ${ }^{17}$

Table 3 CVRP score of the respondents

\begin{tabular}{llll}
\hline & & $\begin{array}{l}\text { Mean CVRP score } \\
(95 \% \mathrm{Cl})\end{array}$ & p Value \\
\hline Medication status & $\begin{array}{l}\text { On medications } \\
\text { Awareness }\end{array}$ & $\begin{array}{l}120.9(117.3 \text { to 124.4) } \\
\text { Not on medications }\end{array}$ & 0.036 \\
& $\begin{array}{l}115.9(112.8 \text { to 119.0) } \\
\text { Aware }\end{array}$ & $121.7(118.5$ to 124.9) & 0.029 \\
& Not aware & $116.7(113.4$ to 119.9) & \\
Control of blood & $\begin{array}{l}\text { Controlled blood } \\
\text { pressure }\end{array}$ & $128.8(121.0$ to 136.7) & 0.009 \\
& $\begin{array}{l}\text { Uncontrolled blood } \\
\text { pressure }\end{array}$ & $118.2(114.3$ to 122.1) & \\
\hline CVRP, cardiovascular risk perception. & &
\end{tabular}

Mohd Azahar NMZ, et al. Heart Asia 2017;9:1-4. doi:10.1136/heartasia-2016-010864 
who found that older individuals have a tendency to underestimate their risk. People who underestimate their risk are actually at a higher risk. This happens because underestimation of risk may not motivate them to adopt a healthy lifestyle including appropriate health-seeking behaviour or even appropriate dietary choices. Our study suggests that healthcare providers need to provide extra effort in educating patients about the consequences of hypertension especially among older individuals. As the person ages, perception of risk turns out to be the key motivational drive to ensure health sustainability. ${ }^{18}$

Hypertensive women tend to have a non-significant lower cardiovascular risk perception score compared with men. Perhaps they perceive that CVD is a male problem. ${ }^{19}$ Schenck-Gustafsson showed that CVD is the most neglected health problem among women in both developing and developed nations. ${ }^{20}$ Another reason for the low cardiovascular risk perception score among women is that they tend to focus on breast cancer and menopause, ${ }^{21}$ thus underestimating their risk for CVD. Empowering women with CVD knowledge is required to avoid the development of this problem among them.

Being single or a divorcee is another factor associated with low cardiovascular risk perception score. Our findings suggest that being single or a divorcee causes lack of motivational or spiritual support. There is evidence from a previous study that motivation and risk perception play an essential role in preventive medicine. ${ }^{22}$

Level of educational attainment is crucial to ensure health sustainability. Majority of people with low educational attainment tend to have lower household income. Subsequently, they will have limited access for health. Furthermore, they will encounter difficulties in affording medicines that are costly. In this study, people who have no formal education underestimated their risk for CVD. Our study conforms to a study conducted by Nsiah-Kumi et $a l^{23}$ who found that individuals with low educational attainment were more likely to have low levels of concern about their risk for certain diseases such as diabetes. ${ }^{23}$ According to the Health Belief Model proposed by Rosenstock et al, ${ }^{6}$ they emphasised that there is a link between patients' perception and educational level on patients' behaviour. ${ }^{6}$

It has been shown that cardiovascular risk perception was significantly associated with household income with the lowest score being observed among respondents with the highest household income. There is evidence that there is a significant relationship between income and heart disease. ${ }^{24} 25$ This mismatch is due to the fact that patients with higher income levels were more likely to be able to afford all necessary medications. ${ }^{26}$ Hence, their dependence on medical appointment or advice from healthcare providers is less. During the medical appointment, there will be a counselling session in which the patient will share their medical problems with their healthcare providers. By conducting counselling, the patient's risk perception could be corrected. ${ }^{27}$

In a study done by Ljubotina et al ${ }^{19}$ they highlight that hypertensives in a rural population are not concerned about their risk to develop CVD. ${ }^{19}$ One of the reasons for this is that people with uncontrolled hypertension are not well informed about the consequences of poorly controlled hypertension. Thus, the percentage of people with uncontrolled hypertension increases yearly.

Perception and compliance are intercorrelated with each other. Patients with good perception will comply with their medication. Hence, perception can act as a predictor for compliance. Ross et $a l^{28}$ illustrate that if the patients perceived that they are at high risk for stroke, they will be concerned with their blood pressure status. ${ }^{28}$ Subsequently, they will comply with their medications. In a study conducted by Petrie and Weinman, ${ }^{29}$ they pointed out that patients with hypertension perceive medication is the key to treat their illness, but a substantial proportion were concerned about taking medicines. ${ }^{29}$

Uncontrolled hypertension remains common despite having effective medical therapy and guidelines in the management of high blood pressure. ${ }^{30}$ One of the significant factors for this poor control of hypertension is compliance. Poor medication compliance has been associated with the behaviour of patients. ${ }^{31}$ Controlling high blood pressure is beneficial for health as well as financial reasons. Optimal management of hypertension has a positive impact on clinical, economic and public consequences. ${ }^{32} 33$ Treating hypertension requires both lifestyle and behavioural changes. Moreover, compliance to medications is a vital step in the regulation of blood pressure. Perception on risk may motivate patients to take medications as prescribed. Knowing how patients perceive hypertension and its complications, doctor-patient relationship is markedly improved leading to better control of blood pressure. ${ }^{1928}$

Many factors are expected to influence the risk perception such as beliefs, knowledge and social circumstances. ${ }^{34}$ Intensive health education could serve as the best tools to ensure our population has adequate perception about their risk of getting CVD. It is important to educate people about the consequences of hypertension.

There are several important clinical and public health implications from our findings. Our study provides an insight into how hypertensives in a rural population perceive their risk for CVD. By knowing patients' perception, effective treatment strategies can be delivered to patients. In our population, there are a limited number of studies with regard to cardiovascular risk perception. Findings from this study may provide useful insight into how hypertensives in rural Malaysia perceive their risk for CVD.

\section{Limitations of the study}

The study has several limitations. First, since this study is a cross-sectional study, we can only describe the factors that were independently associated with cardiovascular risk perception among hypertensives, not attributable causes or temporal inferences on the associations found. Second, this study involved rural communities in Raub, Pahang, potentially limiting the generalisation of the results. Finally, as with any self-reported data concerning sensitive topics, some responses may have been inaccurate. Due to the fear of cardiovascular treatment or surgery, cardiovascular risk factors were potentially under-reported. Nonetheless, this study has provided useful and important information on the perceived risk.

\section{CONCLUSION}

In summary, our study revealed that hypertensives who were not on medications, unaware of their hypertensive status and hypertensives with uncontrolled blood pressures tend to underestimate their risk for future cardiovascular events. Mismatch between actual risk and perceived risk on CVD should be minimised. ${ }^{35}$ Due to the fact that hypertension drives future cardiovascular events ${ }^{36}$ many strategies have to be put in place. Health education is needed to raise perception, awareness and knowledge in the population. Raising awareness and aggressive lifestyle modification among our population are necessary to treat this malady. It is essential to provide the population with adequate information in relation to hypertension followed by strategies to reduce 
the risk of getting it. Consequently, individuals would look at it in a rational and logical manner and implement the risk reduction strategies, thus minimising risk to develop CVD.

\section{Key messages}

\section{What is already known about this subject?}

- Only a few studies pay attention to the perception of individuals with hypertensives in rural areas on their risk of developing cardiovascular disease (CVD).

- Perceived risk has been shown to play an important role in behavioural change.

\section{What does this study add?}

- Hypertensives who were not on medications, unaware of their hypertension and those who had uncontrolled hypertension underestimate their risk for CVD.

\section{How might this impact on clinical practice?}

- This study shows how hypertensives in a rural area perceived their risk of developing future cardiovascular events. Adequate health education may improve this perception, and this may be translated into better blood pressure control.

Acknowledgements The authors would like to express their appreciation to the respondents who participated in this study and staff from the Centre for Translational Research and Epidemiology (CenTRE), Universiti Teknologi MARA, for their technical assistance.

Contributors NMZMA and ADSK were involved in the data collection. NMZMA performed the statistical analysis and wrote the manuscript. NMZMA, ADSK, NHZ and $K Y$ were involved in the critical revision of the manuscript. $K Y$ is the principal investigator of this study. He played a major role in the conception of study design and provided expertise in the critical revision and intellectual content of the manuscript. All authors read and approved the final version.

Funding This work was supported by the Ministry of Higher Education, Malaysia (grant number: 600-RMI/LRGS 5/3 (2/2011)) and the Ministry of Science, Technology and Innovation (grant number: 07-05-IFN BPH 010).

Competing interests None declared.

Patient consent Obtained.

Ethics approval Institutional Ethics Committee.

Provenance and peer review Not commissioned; externally peer reviewed.

(c) Article author(s) (or their employer(s) unless otherwise stated in the text of the article) 2017. All rights reserved. No commercial use is permitted unless otherwise expressly granted.

\section{REFERENCES}

1 Goulding L, Furze G, Birks Y. Randomized controlled trials of interventions to change maladaptive illness beliefs in people with coronary heart disease: systematic review. J Adv Nurs 2010;66:946-61.

2 Barnhart JM, Wright ND, Freeman K, et al. Risk perception and its association with cardiac risk and health behaviors among urban minority adults: the Bronx Coronary Risk Perception study. Am J Health Promot 2009;23:339-42.

3 Cockburn J, Pit S. Prescribing behaviour in clinical practice: patients' expectations and doctors' perceptions of patients' expectations-a questionnaire study. BMJ 1997:315:520-3.

4 Lewis DK, Robinson J, Wilkinson E. Factors involved in deciding to start preventive treatment: qualitative study of clinicians' and lay people's attitudes. BMJ 2003;327:841-7.

5 Rogers RW. A protection motivation theory of fear appeals and attitude change 1. J Psychol 1975;91:93-114.

6 Rosenstock IM, Strecher VJ, Becker MH. Social learning theory and the health belief model. Health Educ Q 1988;15:175-83.

7 Pearson TA, Blair SN, Daniels SR, et al. AHA guidelines for primary prevention of cardiovascular disease and stroke: 2002 update: consensus panel guide to comprehensive risk reduction for adult patients without coronary or other atherosclerotic vascular diseases. American Heart Association Science Advisory and Coordinating Committee. Circulation 2002;106:388-91.
8 Deeks A, Lombard C, Michelmore J, et al. The effects of gender and age on health related behaviors. BMC Public Health 2009;9:213-20.

9 Fernandez RS, Griffiths R, Juergens C, et al. Persistence of coronary risk factor status in participants 12 to 18 months after percutaneous coronary intervention. J Cardiovasc Nurs 2006;21:379-87.

10 Furze G, Bull P, Lewin RJ, et al. Development of the York Angina Beliefs Questionnaire. J Health Psychol 2003;8:307-15.

11 Smith SC, Feldman TE, Hirshfeld JW, Smith J, Sidney C, et al. ACC/AHA/SCAI 2005 guideline update for percutaneous coronary intervention: a report of the American College of Cardiology/American Heart Association Task Force on Practice guidelines (ACC/AHA/SCAI Writing Committee to Update the 2001 Guidelines for Percutaneous Coronary Intervention). J Am Coll Cardiol 2006;47:e1-21.

12 Davidson PM, Salamonson Y, Rolley J, et al. Perception of cardiovascular risk following a percutaneous coronary intervention: a cross sectional study. Int I Nurs Stud 2011:48:973-8.

13 Nawawi HM, Nor IM, Noor IM, et al. Current status of coronary risk factors among rural Malays in Malaysia. J Cardiovasc Risk 2002;9:17-23.

14 Renner B, Schwarzer R. Risk and Health Behaviors. Documentation of the scales of the research project: "Risk Appraisal Consequences in Korea" RACK. International University Bremen \& Freie Universität Berlin, 2005.

15 Azahar NM, Ambigga KS, Saman SA, et al. Risk perception on cardiovascular disease among adults in rural population in Malaysia: a pilot study on translation and validation of the Risk and Health Behaviour Questionnaire. Indian J App/ Res 2014;4:71-2.

16 Honda K, Neugut Al. Associations between perceived cancer risk and established risk factors in a national community sample. Cancer Detect Prev 2004;28:1-7.

17 Hunt SM, McEwen J, McKenna SP. Perceived health: age and sex comparisons in a community. J Epidemiol Community Health 1984;38:156-60.

18 Renner B, Spivak Y, Kwon S, et al. Does age make a difference? Predicting physical activity of South Koreans. Psychol Aging 2007;22:482-93.

19 Ljubotina A, Materljan E, Mićović V, et al. Perception of arterial hypertension and myocardial infarction in hypertensive and normotensive men and women. Coll Antropol 2011;35:147-53.

20 Schenck-Gustafsson K. Risk factors for cardiovascular disease in women. Maturitas 2009;63:186-90.

21 Oliver-Mcneil S, Artinian NT. Women's perceptions of personal cardiovascular risk and their risk-reducing behaviors. Am J Crit Care 2002;11:221-7.

22 Dearborn JL, McCullough LD. Perception of risk and knowledge of risk factors in women at high risk for stroke. Stroke 2009;40:1181-6.

23 Nsiah-Kumi PA, Ariza AJ, Mikhail LM, et al. Family history and parents' beliefs about consequences of childhood overweight and their influence on children's health behaviors. Acad Pediatr 2009;9:53-9.

24 Langenberg C, Shipley MJ, Batty GD, et al. Adult socioeconomic position and the association between height and coronary heart disease mortality: findings from 33 years of follow-up in the Whitehall Study. Am J Public Health 2005;95:628-32.

25 Manderbacka K, Hetemaa T, Keskimäki I, et al. Are there socioeconomic differences in myocardial infarction event rates and fatality among patients with angina pectoris? J Epidemiol Community Health 2006;60:442-7.

26 Alter DA, Iron K, Austin PC, et al. Socioeconomic status, service patterns, and perceptions of care among survivors of acute myocardial infarction in Canada. JAMA 2004:291:1100-7.

27 Barnhart J, Lewis V, Houghton JL, et al. Physician knowledge levels and barriers to coronary risk prevention in women: survey results from the Women and Heart Disease Physician Education Initiative. Womens Health Issues 2007;17:93-100.

28 Ross S, Walker A, MacLeod MJ. Patient compliance in hypertension: role of illness perceptions and treatment beliefs. J Hum Hypertens 2004;18:607-13.

29 Petrie KJ, Weinman J. Why illness perceptions matter. Clin Med 2006;6:536-9.

30 Haynes RB, McDonald HP, Garg AX. Helping patients follow prescribed treatment: clinical applications. JAMA 2002;288:2880-3.

31 Holt EW, Muntner P, Joyce CJ, et al. Health-related quality of life and antihypertensive medication adherence among older adults. Age Ageing 2010:39:481-7.

32 Marković BB, Kranjcević K, Stojanović-Spehar S, et al. Treatment of hypertension by general practitioners and antihypertensive drugs expenditure in an urban environment. Coll Antropol 2009;33:71-6

33 Stason WB. Hypertension: a policy perspective, 1976-2008. J Am Soc Hypertens 2009;3:113-8

34 Patel S, Bhopal R, Unwin N, et al. Mismatch between perceived and actual overweight in diabetic and non-diabetic populations: a comparative study of South Asian and European women. J Epidemiol Community Health 2001;55:332-3.

35 Nazar A, Zakaria I, Rahimi H, et al. Mismatch between actual risk and perceived risk for cardiovascular disease among elderly in a rural population of Malaysia [abstract]. $J$ Hypertens 2016;34:e459.

36 Azahar NMZ, Devi A, Saman MSA, et al. Hypertension is the main driver for future cardiovascular events: insight from Framingham risk score in a developing nation [abstract]. J Hypertens 2012;30:e96-7. 